\title{
A SCIENTOMETRIC STUDY ON THE JOURNAL RUBBER CHEMISTRY AND TECHNOLOGY: 2005 -2014
}

\author{
M.ARUNMOZHI ${ }^{1} \&$ N.THILAGAVATHY ${ }^{2}$ \\ ${ }^{1}$ Research Scholar, Bharathiar University, Librarian, K.C.S. Kasi Nadar College, Coimbatore, Tamil Nadu, India \\ ${ }^{2}$ Librarian, Dr. M. G. R. Janaki College of Arts \& Science, Chennai, Tamil Nadu, India
}

\begin{tabular}{|l|}
\hline ABSTRACT \\
Scientometric analysis of 436 articles, published in "Rubber Chemistry and Technology" has carried out. Ten \\
volumes of the journal, containing 45 issues from 2005-2014, has been taken into consideration in the present study. The \\
number of contributions, authorship pattern \& author productivity, average length of article keywords and collaborative \\
papers, has been analyzed. Out of 436 contribution 65, are single authored and the rest is, by multi authored with degree \\
of collaboration 0.85 patterns of Co-Authorship revealed that, the improving trend of co-authored papers. \\
KEYWORDS: Scientometric, Rubber Chemistry and Technology, Author Productivity
\end{tabular}

Received: Jul 28, 2017; Accepted: Aug 17, 2017; Published: Sep 07, 2017; Paper Id.: IJAPBCROCT20171

\section{INTRODUCTION}

Scientometric can be defined as the "Quantitative study of science, communication in science, and science policy" (Hess, 1997, 75). Scientometric is the study of measuring and analyzing, science \& technology and innovation. In practice, Scientometric is often done, using bibliometrics, which is a measurement of the impact of (scientific) publications. Modern scientometrics is mostly based on the work of Derek J.de solla price and Eugene Garfield. The latter founded the institute for scientific information, which is ardently used in scientometric analysis methods of research includes qualitative, quantitative and computational approaches. One significant finding in the field is a principle of cost escalation, to the effect that, achieving further findings at a given level of importance grow exponentially more costly in the expenditure of effort and resources.

\section{Importance of Scientometric Studies}

- To determine the size of the scholarly enterprise.

- The productivity of scholarly authors.

- Geographical origin.

- Form of transmission.

- To know the medium of communication.

- The amount of information conveyed.

- Pertinence and relevance of information to society.

\section{SOURCE JOURNAL}


Rubber chemistry and technology was selected, as the source journal for the present research. The journal was established in 1928, with "Carroll C. Davis", as its first editor-in-chief. It is published by the American chemical society Rubber Division. RCT is a quarterly peer-reviewed scientific journal covering research, technical developments, and chemical engineering, relating to Rubber and its allied substances. The journal currently publishes four issues per year. One issue is dedicated to reviews of topics in rubber science, including a review by the most recent Good year medalist. The remaining issues contain original research contribution.

\section{OBJECTIVES OF THE STUDY}

- To study year wise growth.

- To study the authorship pattern.

- To study the period and volume wise authorship pattern.

- To study authors productivity.

- To examine the single and multi authored papers of the journal and,

- Degree of collaboration.

\section{SCOPE AND METHODOLOGY}

The present study aims to find out, the authorship and collaboration pattern, average length of articles and average keywords, in the source journal. Ten volumes (Vol.No.78 to 87) of journal of Rubber chemistry and technology, published between 2005-2014, containing 45 issues have been taken into consideration, in the present study. The details regarding number of papers, nature of author, keywords and length of papers are collected, to fulfill the objectives of the present study. The collected data were analyzed, with the following bibliometrics indicators.

- $\quad$ Extent of authorship pattern (Single vs multiple)

- Degree of collaboration.

Table 1: Year Wise Distribution of Articles

\begin{tabular}{|c|c|c|c|c|}
\hline Year & Vol. No & No. of. Issues & Total No. of. Articles & \% of Articles \\
\hline $\mathbf{2 0 0 5}$ & 78 & 5 & 58 & $12.94 \%$ \\
\hline $\mathbf{2 0 0 6}$ & 79 & 5 & 51 & $11.38 \%$ \\
\hline $\mathbf{2 0 0 7}$ & 80 & 5 & 53 & $11.83 \%$ \\
\hline $\mathbf{2 0 0 8}$ & 81 & 5 & 45 & $10.04 \%$ \\
\hline $\mathbf{2 0 0 9}$ & 82 & 5 & 33 & $7.36 \%$ \\
\hline $\mathbf{2 0 1 0}$ & 83 & 4 & 28 & $6.25 \%$ \\
\hline $\mathbf{2 0 1 1}$ & 84 & 4 & 37 & $8.25 \%$ \\
\hline $\mathbf{2 0 1 2}$ & 85 & 4 & 41 & $9.15 \%$ \\
\hline $\mathbf{2 0 1 3}$ & 86 & 4 & 43 & $9.59 \%$ \\
\hline $\mathbf{2 0 1 4}$ & 87 & 4 & 47 & $10.77 \%$ \\
\hline \multicolumn{2}{|c|}{ Total } & $\mathbf{4 5}$ & $\mathbf{4 3 6}$ & $\mathbf{1 0 0 \%}$ \\
\hline
\end{tabular}

Table: 1, shows the distribution of articles published in the journal of Rubber Chemistry and Technology, during 2005-2014. Out of 436 articles, the highest numbers of articles were published, in the year 2005, with 58 articles (12.94\%), followed 28 articles are the lowest numbers of articles were published in the year $2010(6.25 \%)$ 
Table 2: Authorship Pattern

\begin{tabular}{|l|c|c|}
\hline Authors & No. of. Papers & $\mathbf{\%}$ \\
\hline Single & 65 & $14.90 \%$ \\
\hline Two & 88 & $20.18 \%$ \\
\hline Three & 109 & $25.00 \%$ \\
\hline Four & 87 & $19.95 \%$ \\
\hline$>$ Four & 86 & $19.72 \%$ \\
\hline Total & $\mathbf{4 3 6}$ & $\mathbf{1 0 0}$ \\
\hline
\end{tabular}

It is observed from the Table 2, about $80 \%$ of papers was contributed by multiple authors. Out of 436 papers, the highest number of papers was published by three authors and it accounts for 109 with $25.00 \%$, followed by a double authored articles account, for 88 with $20.18 \%, 19.95 \%$ \& $19.72 \%$ of articles were published, by four and more than four authors. $14.90 \%$ of articles were published by single authors. (But the trend of the author pattern in the journal shows that the team size was two to four)

Table 3: Authorship Pattern Year Wise

\begin{tabular}{|c|c|c|c|c|c|}
\hline Year & \multicolumn{5}{|c|}{ Authors } \\
\hline & $\mathbf{1}$ & $\mathbf{2}$ & $\mathbf{3}$ & $\mathbf{4}$ & $\mathbf{7 4}$ \\
\hline $\mathbf{2 0 0 5}$ & 7 & 10 & 16 & 15 & 10 \\
\hline $\mathbf{2 0 0 6}$ & 8 & 19 & 12 & 9 & 3 \\
\hline $\mathbf{2 0 0 7}$ & 10 & 9 & 20 & 8 & 6 \\
\hline $\mathbf{2 0 0 8}$ & 6 & 10 & 8 & 11 & 10 \\
\hline $\mathbf{2 0 0 9}$ & 6 & 8 & 10 & 1 & 8 \\
\hline $\mathbf{2 0 1 0}$ & 7 & 7 & 7 & 3 & 5 \\
\hline $\mathbf{2 0 1 1}$ & 5 & 10 & 11 & 6 & 5 \\
\hline $\mathbf{2 0 1 2}$ & 8 & 6 & 7 & 12 & 8 \\
\hline $\mathbf{2 0 1 3}$ & 6 & 6 & 4 & 14 & 12 \\
\hline $\mathbf{2 0 1 4}$ & 2 & 3 & 14 & 9 & 19 \\
\hline Total & $\mathbf{6 5}$ & $\mathbf{8 8}$ & $\mathbf{1 0 9}$ & $\mathbf{8 8}$ & $\mathbf{8 6}$ \\
\hline
\end{tabular}

Table: No: 3, Regarding single authored contributions, the year 2007 have the highest contribution with 10 articles and the lowest in 2011, with 5 articles. Regarding double authored contributions, 2006 has the highest contribution with 19 articles. The Year $2007 \& 2005$ has the highest contribution, with $20 \& 15$ articles, regarding three and four authors. The year 2014, has the highest contributions of multi authored (More than five authors), with 19 articles.

Table 4: Author Productivity

\begin{tabular}{|c|c|c|c|c|}
\hline Year & Total. No. of. Papers & Total No. of Authors & AAPP & Productivity per Author \\
\hline $\mathbf{2 0 0 5}$ & 58 & 185 & 3.18 & 0.31 \\
\hline $\mathbf{2 0 0 6}$ & 51 & 133 & 2.60 & 0.38 \\
\hline $\mathbf{2 0 0 7}$ & 53 & 150 & 2.83 & 0.35 \\
\hline $\mathbf{2 0 0 8}$ & 45 & 144 & 3.2 & 0.31 \\
\hline $\mathbf{2 0 0 9}$ & 33 & 96 & 2.90 & 0.34 \\
\hline $\mathbf{2 0 1 0}$ & 28 & 79 & 2.82 & 0.35 \\
\hline $\mathbf{2 0 1 1}$ & 37 & 107 & 2.89 & 0.34 \\
\hline $\mathbf{2 0 1 2}$ & 41 & 129 & 3.14 & 0.31 \\
\hline $\mathbf{2 0 1 3}$ & 43 & 146 & 3.39 & 0.29 \\
\hline $\mathbf{2 0 1 4}$ & 47 & 207 & 4.40 & 0.22 \\
\hline Total & $\mathbf{4 3 6}$ & $\mathbf{1 3 7 6}$ & $\mathbf{3 . 1 5}$ & $\mathbf{0 . 3 1}$ \\
\hline
\end{tabular}

Table No.4 shows that, the total average number of authors per paper is 3.15 , for the 436 articles. The average 
productivity per author is 0.31 , during the year 2005 - 2014. Productivity has been calculated with the following formula.

Average Authors per paper $=$ No. of Author $/$ No. of papers

Productivity per Author = No. of papers / No. of Authors

Table 5: Degree of Collaboration

\begin{tabular}{|c|c|c|c|}
\hline Year & Single & Multiple & DC \\
\hline $\mathbf{2 0 0 5}$ & 7 & 51 & 0.87 \\
\hline $\mathbf{2 0 0 6}$ & 8 & 43 & 0.84 \\
\hline $\mathbf{2 0 0 7}$ & 10 & 43 & 0.81 \\
\hline $\mathbf{2 0 0 8}$ & 6 & 39 & 0.86 \\
\hline $\mathbf{2 0 0 9}$ & 6 & 27 & 0.81 \\
\hline $\mathbf{2 0 1 0}$ & 7 & 22 & 0.75 \\
\hline $\mathbf{2 0 1 1}$ & 5 & 32 & 0.86 \\
\hline $\mathbf{2 0 1 2}$ & 8 & 33 & 0.80 \\
\hline $\mathbf{2 0 1 3}$ & 6 & 36 & 0.85 \\
\hline $\mathbf{2 0 1 4}$ & 2 & 45 & 0.95 \\
\hline Total & $\mathbf{6 5}$ & $\mathbf{3 7 1}$ & $\mathbf{0 . 8 5}$ \\
\hline
\end{tabular}

To determine the Degree of collaboration (DC), the following formula suggested by K. Subramanyam (1983) is employed here:

$\mathrm{Dc}=(\mathrm{Nm} / \mathrm{Nm})+\mathrm{Ns}$

Where,

Dc $=$ Degree of Collaboration

$\mathrm{Nm}=$ Number of Multiple Authored papers

Ns $=$ Number of single Authored papers

The Degree of a collaboration of authors, by year wise, is presented in table 5. The degrees of collaboration rank from 0.75 to 0.87 . The average degree of collaboration is 0.85 , during the period $2005-2014$, and it brings out clearly that, there exists a higher level of collaboration with the journal.

Table 6: Distribution of Pages

\begin{tabular}{|c|c|c|c|}
\hline Year & No. of. Article & Total Pages & Average Pages per Articles \\
\hline $\mathbf{2 0 0 5}$ & 58 & 909 & 15.67 \\
\hline $\mathbf{2 0 0 6}$ & 51 & 891 & 17.47 \\
\hline $\mathbf{2 0 0 7}$ & 53 & 906 & 17.09 \\
\hline $\mathbf{2 0 0 8}$ & 45 & 880 & 19.55 \\
\hline $\mathbf{2 0 0 9}$ & 33 & 540 & 16.36 \\
\hline $\mathbf{2 0 1 0}$ & 28 & 426 & 15.21 \\
\hline $\mathbf{2 0 1 1}$ & 37 & 593 & 16.02 \\
\hline $\mathbf{2 0 1 2}$ & 41 & 670 & 14.25 \\
\hline $\mathbf{2 0 1 3}$ & 43 & 678 & 15.76 \\
\hline $\mathbf{2 0 1 4}$ & 47 & 679 & 14.44 \\
\hline Total & $\mathbf{4 3 6}$ & $\mathbf{7 1 7 2}$ & $\mathbf{1 6 . 4 4}$ \\
\hline
\end{tabular}

Table 6, reveals that, 436 papers published with a total page 7172 (average 16.44 pages per article), during the year 2005 - 2014. It is observed that, the average length of the article varied from a minimum of 14.25 pages, to a maximum of 19.55 pages. 


\section{FINDINGS AND CONCLUSIONS}

The analysis reveals the following conclusions.

- $\quad$ The maximum number of papers published in 2005 and minimum in 2010.

- The highest number of articles contributed by multiple authors during the study period.

- $\quad$ The degree of collaboration was 0.85 .

- The author productivity is 0.31 and the average number of authors per paper is 3.15 .

- $\quad$ The average pages per paper are 16.44

- The year - wise distribution has been shown in this study.

\section{REFERENCES}

1. De solla price D. editorial statement. Scientometrics volume 1. Issue 1 (1978).

2. http://scholarlyoa.com /2014/03/06/is the editor of the Springer-Journal-Scientometrics

3. Edge, D (1979) Quantitative Measures of communication in science: A critical overview. Hist. Sci., 17,102-134.

4. Eggle, L. (2006). Theors and practice of the g-index. Scientometrics (69(i)(131-152)

5. De sola price P. J. Little Science, Big Science. New York: Columbia university press; 1963.

6. Nattar s, (2011) “Indian Journal of chemistry: A Scientometric Analysis”. International Journal of Library and Information Studies, 1 (1): 7-15. 
